\title{
Science, Technology and the Public
}

\section{Christopher Coenen}

Published online: 21 June 2018

(C) Springer Nature B.V. 2018

The current issue of our journal features a variety of articles that in one way or another contribute to a better understanding of a crucial topic in scholarship on new and emerging technologies: the role and perceptions of the (lay) public in science, technology and innovation systems.

I am particularly happy that, after a number of pertinent articles (by Lilian van Hove and Fern Wickson; Mikael Johansson and Åsa Boholm; Rider Foley, Arnim Wiek and Braden Kay; and Andy Miah) were published in Volume 11 (2017) of NanoEthics. Studies of New and Emerging Technologies, the current issue again features an excellent article on the ways nanoscientists view and understand engagement of and with the public in their field. In her interview-based study, Regula Valérie Burri explores how scientists in Switzerland regard public engagement initiatives, and analyses how researchers conceive of and imagine science-society interactions in the early phases of research and technology development. Focusing on experts' implicit framing of the roles played by citizens, scientists and the public, the author identifies four different models (educational, paternalistic, elitist and economistic) for nanoscientists' understanding of public engagement. Burri discusses these models against the backdrop of the dialogue model of public engagement promoted by many social scientists

C. Coenen $(\bowtie)$

Institute for Technology Assessment and Systems Analysis (ITAS), Karlsruhe Institute of Technology (KIT), POB 3640, 76021 Karlsruhe, Germany

e-mail: christopher.coenen@kit.edu and policymakers. Her conclusions suggest that public engagement with research and technology development may be deemed an ever-changing, politically contested terrain in which the concept of 'responsible research and innovation' (RRI) can serve as a kind of regulative ideal.

In their article for the current issue, António Carvalho and João Arriscado Nunes revisit a deliberative forum on nanotechnologies that took place in Portugal almost ten years ago and remains a unique event in that country. It was conducted as part of the important European project DEEPEN (Deepening Ethical Engagement and Participation in Emerging Nanotechnologies), the results of which have been presented and discussed many times in our journal. Whereas the authors concentrated on methodological aspects of the matter in an earlier contribution that was published in our August 2013 issue, they now discuss the tensions, and asymmetries of power and knowledge between scientists, science communicators and members of the lay public that came to light at this forum. In a fascinating reflection on their own role as social scientists facilitating this public engagement activity, the authors also make a number of suggestions for an expansion of the methodological repertoire available to those who run such events, which they present as a means to respond to the power and knowledge asymmetries between scientists and members of the lay public that are so hard to overcome.

The other three articles in the current issue that exclusively deal with the nanofield do not focus on the role of the public in the governance of and deliberations on 
science, technology and innovation, but nevertheless have important things to say about public engagement with and perceptions of the field. In his article, Antoni Roig makes a case for IT-based nanotechnology governance platforms to regularly perform co-regulatory tasks, taking account not only of safety aspects but also of public interests more generally. In his opinion, the platforms should draw on an RRI perspective that allows such interests to be systematically factored into these activities. Safety is in any case a major public concern when it comes to new and emerging science and technology, and this is still true for applications of nanoscience and nanotechnologies as well. In our April issue, an article by Kristen Lyons and Naomi Smith raised concerns about the use of nanoparticles in the food system in Australia, sharply criticising Food Standards Australia New Zealand (FSANZ). In our current issue, FSANZ's Chief Executive Officer, Mark Booth, responds to the criticism in detail, contradicting several of the claims made in Lyons and Smith's article, and emphasising the importance of providing the public with accurate information on food safety. In line with our policies concerning 'Response' articles, his response and the original article by Lyons and Smith are cross-linked. Another contribution to the current issue that addresses aspects of nanosafety is an article by Homero Fernando Pastrana, Alba Avila and Candace Tsai on the use of nanomaterials in cosmetic products. After reviewing the regulatory systems for cosmetics on the main global markets, they conclude that only the European Commission has established specific requirements for nanomaterials in products of this kind. The authors warn against any further delay in the creation of a harmonised multilateral framework, pointing to the International Cooperation on Cosmetic Regulation (ICCR) initiative as a remarkable effort in this regard.

In her instructive, thought-provoking article, Claudia Schwarz-Plaschg explores the power of analogies in debates about science and technology, focusing on nanotechnology but with a broader thematic scope. She asks how analogies could be employed effectively and responsibly in order to imagine and govern emerging technologies in general, and nanotechnology in particular. After discussing the concept of analogical imagination, and the explorative and anticipatory potential of analogies, Schwarz-Plaschg analyses how analogies can frame discourse on emerging technologies in specific ways, which are also relevant as far as technology assessments, funding policies and approaches to governance are concerned. From her perspective, analogical imagination, and a sensibility to framing and persuasive effects can foster RRI, but only if policy makers, industry and other groups of actors that strategically deploy analogies do so in a responsible manner, something that means welcoming critical scrutiny of their analogies as well. Furthermore, Schwarz-Plaschg emphasises that citizens who participate in public engagement activities should be supported in thinking through existing analogies, and reflecting on their constructed nature and their functions in discourse.

An important tool for encouraging reflection on new and emerging technoscience is presented in an article by Marjoleine van der Meij, Anouk Heltzel, Jacqueline Broerse and Frank Kupper, who examine the field of synthetic biology (which is often covered in our journal) as a case study. Their work is centred around inclusive reflection on how people frame this field, and they describe their facilitation of such reflection with the Frame Reflection Lab (FRL) method. Building upon playfulness design principles, an FRL comprises a workshop with video-narratives and co-creative group exercises. Based on the results and analysis of workshops, group conversations and mini-exit surveys they conducted, the authors identified and analysed various patterns within frame reflection. The article also includes a number of recommendations concerning the methodology for frame reflection and potential future uses of the FRL method. As someone who had the pleasure to take part in events organised by the authors under the auspices of the SYNENERGENE project - and in several events that were similar in terms of their methodology -, I can confirm that engagement activities with a strong element of playfulness can work particularly well in fields marked by public controversies and hardened lines of conflict.

Last but not least, I would like to inform you that a number of updates to our journal's homepage will be made during the summer. Among other things, a new Aims and Scope section will replace the current one, a detailed description of each of the quite numerous article categories featured in our journal will be uploaded in the Instructions for Authors section, and the Additional Information section will be updated. So, please watch out for changes when visiting us online and enjoy the current issue! 